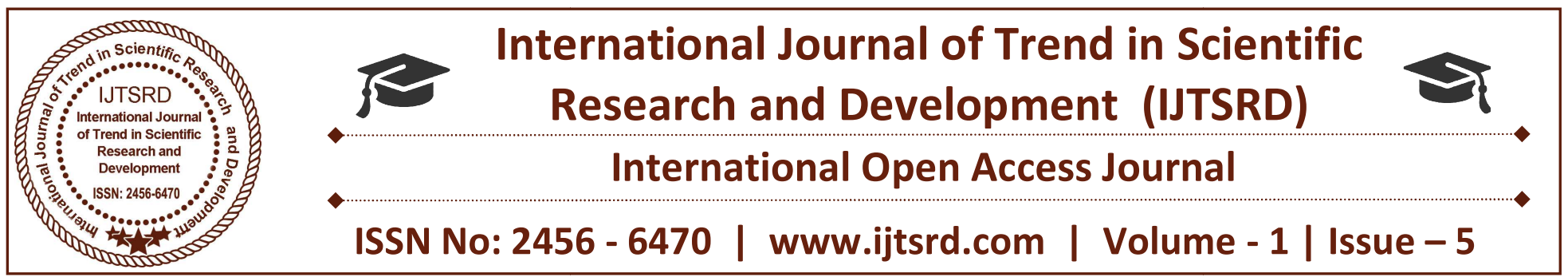

\title{
Impact Analysis on Skill Development with Abacus Users
}

\author{
Yogesh Tiwari \\ School of Management Studies, \\ North Maharashtra University, Jalgaon, \\ Maharashtra, India
}

\author{
Dr. Pavitra Patil \\ Assistant Professor, School of Management \\ Studies, North Maharashtra University, Jalgaon, \\ Maharashtra, India
}

\begin{abstract}
From recent time Abacus program was used by Chinese, Japanese, Malaysians and Koreans to improve mathematical skills. The improvement in mathematical skills is due to a coordinated functioning of both right and left brain hemisphere. As learning and memory in any field is achieved by coordinating and analyzing the different sensory inputs, whether an abacus learner would also improve the short term memory. A group of 20 children of average IQ between 7 and 12 years from an abacus institute were evaluated for short term memory before and after a period of one and two years. The results showed that the abacus learners at the end of one and two years had a better visual and auditory memory with ability and positive attitude when compared to non abacus learners
\end{abstract}

Keywords: Abacus, Non- abacus learners, visualization, dictation, concentration, performance and skill development

\section{INTRODUCTION}

From ancient time Abacus was used by Chinese, Japanese Malaysians and Koreans to improve the mathematical skills. Abacus is a calculating instrument, a mechanical aid which is performed by moving beads along rods, using both hands. In India from last 15 years abacus started first at metropolitan city in massive manner and then in small town for last 6-8 years. There are different levels in abacus. At the end of the level II, Abacus learners solve mathematical problems without using abacus instrument but by visualization of beads in the brain. It has been well documented that along with mathematical skills there is an increase in concentration, learning power, grasping power, memory, listening skills, observation skills, analytical skills in Abacus learners when compared to NonAbacus learners of the same age [1]. Abacus learner's uses co-ordination of light, sound and finger movements thus increases the synaptic connections. The abacus learner tries to coordinate visual, auditory and sensory inputs simultaneously analyses the problems and solves them. Abacus learner's co ordinate right and left hemispheres to solve problems.

The action of the (R) hand helps in developing the logical thinking and language function of the (L) hemisphere and the action of the (L) hand in developing creative, imaginary and 3-dimensional skills of (R) brain. Since the (R) \& (L) hemisphere transmit messages to each other and functions the whole brain $[2,3,4]$. That is well known as complete brain development program. Learning is accession of the information whereas memory is the retention and storage of the information which is recalled and used for further learning. So learning leads to memory and learning becomes better by association with memory. The abacus learners are trained to co-ordinate visual, auditory and sensory inputs and solve problems by analyzing these repeatedly [5]. Though number of studies has proved the influence of abacus in improving mathematical skills, its influence on memory and over all learning ability ha s not been 
evaluated so far. All these leads to increase in VAK, skills confidence as well as ability \& positivity in abacus learners $[6,7,11]$.

\section{AIM}

The aim of our study is to growth of skills after using abacus in each level such as confidence development, ability \& positivity approach in children between age of 7 and 12 years who have been trained in abacus for one year.

\section{MATERIAL AND METHODS}

Children between 7-12 years and between standard IIVI were selected for the study from the following center: - Genius brain Academy Bhusawal and ICD Abacus Bhusawal.

Students from both the centers were collected a total of 20 students a batch for study of one years during March 2016 to April 2017. The children enrolled belong to the upper middle class families with $45 \%$ parent's graduates. Before staring Tests for IQ were done using Binet Kamet Scale and students with average IQ were included in the study. The children included in the study had undergone 1 to 3 level of training. Each level consisted of 3 months, in which the children had classes twice weekly during weekends (Saturday and Sunday). Alternate days in summer holidays were conducted. Each class extended for a period of one hour. After every level there was a break of one week during which the children were asked to practice abacus at home before they pass on to the next level. In I \& II level, children were taught addition and subtraction using Abacus. In III level, multiplication. At all these levels, children were trained to solve mathematical problems using Abacus beads and then by visualize the bead movements form Level II onwards. In each level the competency was increase in rows and columns.

\section{Level 1-INCLUSION CRITERIA:}

1) Age 7-12 years.

2) A preliminary test for intelligence was conducted and children with average IQ were selected. 3)
Students who underwent abacus training regularly for a period of one years.

\section{Level 2- EXCLUSION CRITERIA:}

\section{1) Children with IQ above or below average.}

2) Subjects with visual, hearing or other neurological problems.

This study was done in between March 2016 and April 2017.The children were divided into 4 groups.

Group I: $(n=20) 7-12$ years of age of non abacus learners of average IQ acted as control (March 2016 and April 2017).

Group II: $(n=20)$ Children between $7-12$ years of age of average IQ who had completed level I (March 2016 and April 2017).

Group III: (n=20) Children between 7-12 years of age of average IQ who had completed level II (March 2016 and April 2017).

Group IV: (n=20) Children between 7-12 years of age of average IQ who had completed level III (March 2016 and April 2017).

\section{A. Tests for IQ:}

Tests for IQ are done for Children between 7 and 12 years. These tests are age specific. We use the Binet Kamet scale to assess the IQ of all the children enrolled in our study. The student should start answering from the tests designed for 5 years of age and goes up to the maximum that he is able to achieve. If he fails to answer all the questions in that test, he is considered to have an IQ of that particular age and he cannot pass to the next age. The formula used to calculate IQ, IQ $=\mathrm{MA} / \mathrm{CA} \times 100$ Where MA stands for mental age and CA stands for chronological age of the individual whose intelligence is being tested.

\section{B. Tests for memory:}

At the end of each level a test was conducted to study the development of various skills. At the end of level I test was used to study the concentration level, motivation skills with the help of abacus sums of 
addition and subtraction. At the end of Level II development of visualization skills are developed which is predicted by using visualization sums along with this level of concentration, memory and motivation skills are developed using higher sums of addition and subtraction. At the end of Level III skills such retention and recall are also developed by higher sums of addition, subtraction and multiplication and fully visualization is developed by doing the same sums.

\section{Test for whole Brain development:-}

In each class the learners were told to use both hands for solving sums, regular use of both hand for writing in speed writing used their both parts of brain. At the end of level II they were targeted with the time limit which enhanced their concentration, memory, retention and recall skills at speedy level.

\section{RESULTS \& DISCUSSION:-}

Table 1: Statistical data of abacus learners

\begin{tabular}{|l|l|l|l|l|l|}
\hline N=20 & Max & Min. & Avg. & Std. Dev \\
\hline \multirow{2}{*}{ Before staring abacus training } & 39 & 17 & 28 & 6 \\
\hline \multirow{4}{*}{ Level I } & On abacus & & & & \\
\cline { 2 - 6 } & Dictation & 57 & 37 & 49 & 5 \\
\cline { 2 - 6 } & Overall view & $\mathbf{9 6}$ & $\mathbf{6 1}$ & $\mathbf{8 0}$ & $\mathbf{9 . 8}$ \\
\hline \multirow{4}{*}{ Level II } & On abacus & 48 & 21 & 37 & 7 \\
\cline { 2 - 6 } & Visualization & 40 & 20 & 30 & 5 \\
\cline { 2 - 6 } & Dictation on abacus & 10 & 4 & 7 & 2 \\
\cline { 2 - 6 } & Overall view & $\mathbf{9 8}$ & $\mathbf{4 5}$ & $\mathbf{7 4}$ & $\mathbf{1 2 . 8}$ \\
\hline \multirow{4}{*}{ Level III } & On abacus & 29 & 17 & 23 & 3 \\
\cline { 2 - 6 } & Dictation on abacus & 19 & 9 & 15 & 3 \\
\cline { 2 - 6 } & Visualization sums & 27 & 10 & 22 & 4 \\
\cline { 2 - 6 } & Dictation by visualization & 18 & 7 & 13 & 5 \\
\cline { 2 - 6 } & Overall view & $\mathbf{9 2}$ & $\mathbf{4 3}$ & $\mathbf{7 2}$ & $\mathbf{1 2}$ \\
\hline
\end{tabular}

$N$ means number of abacus learners.

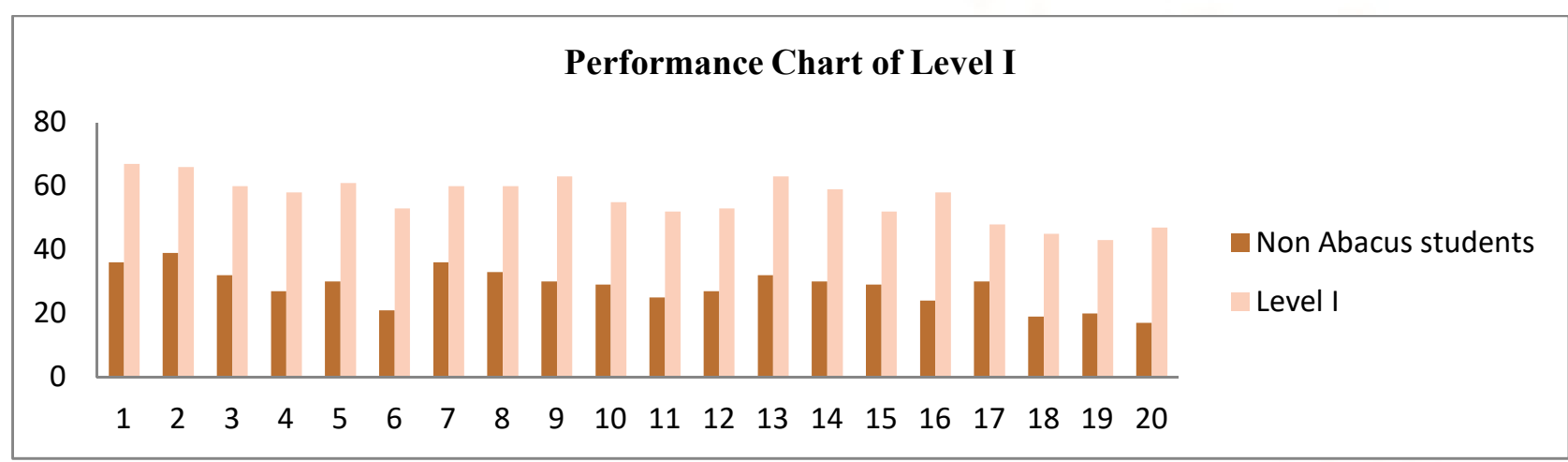

Fig 1. Performance chart of abacus and non-abacus learners after level I 


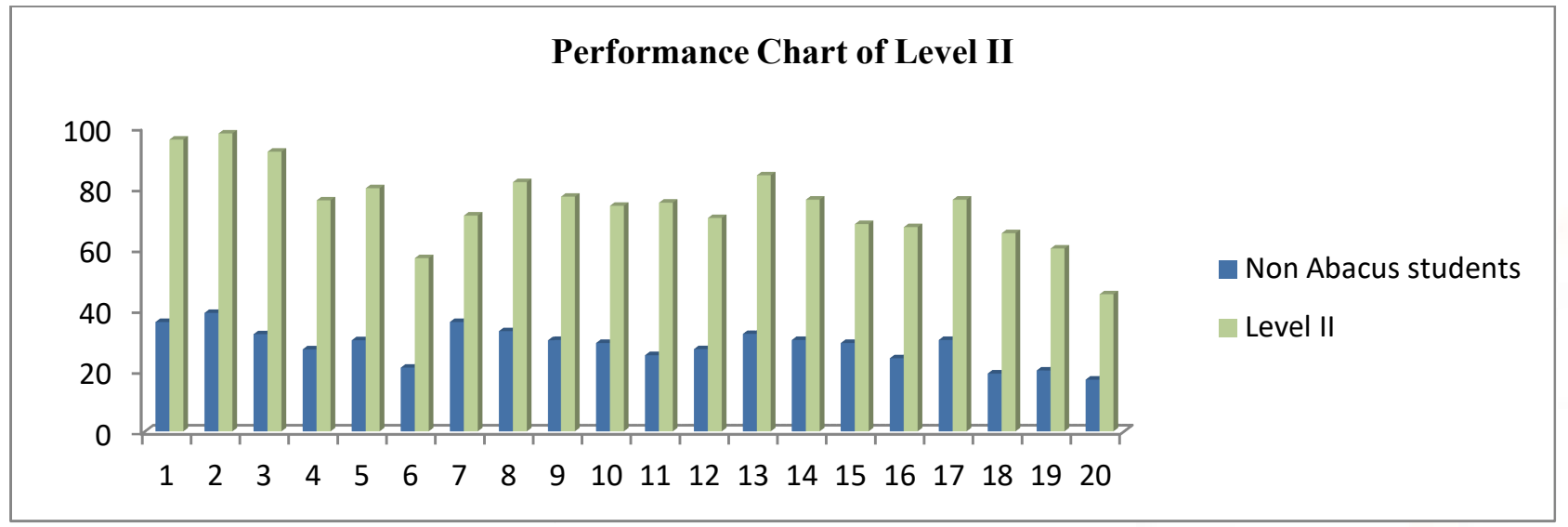

Fig 2. Performance chart of abacus and non-abacus learners after level II

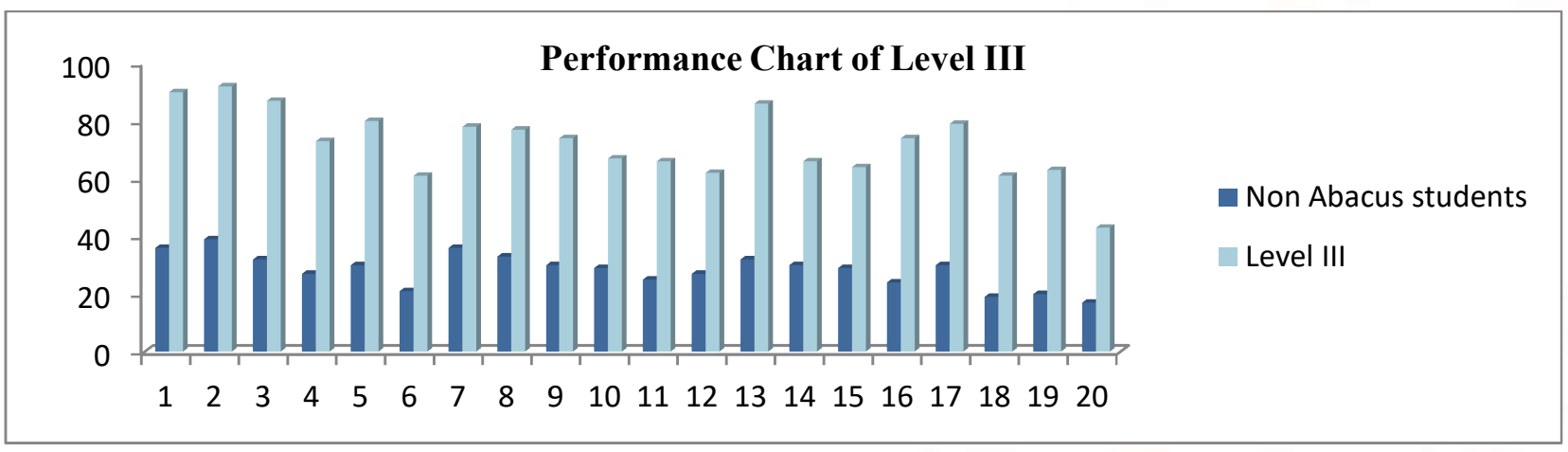

Fig 3. Performance chart of abacus and non-abacus learners after level III

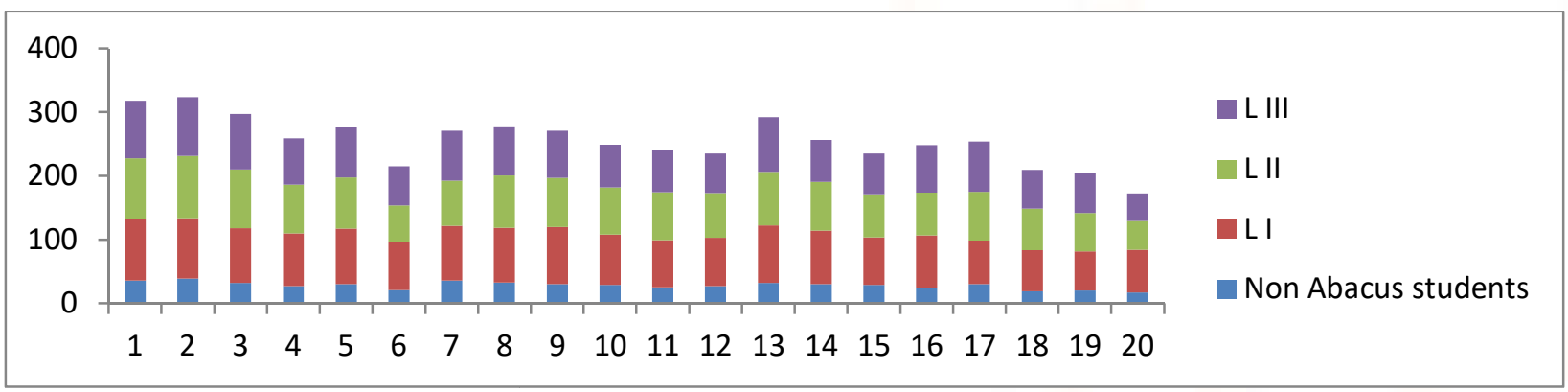

Fig 4. Individual Comparison Performance chart of abacus learners in each level

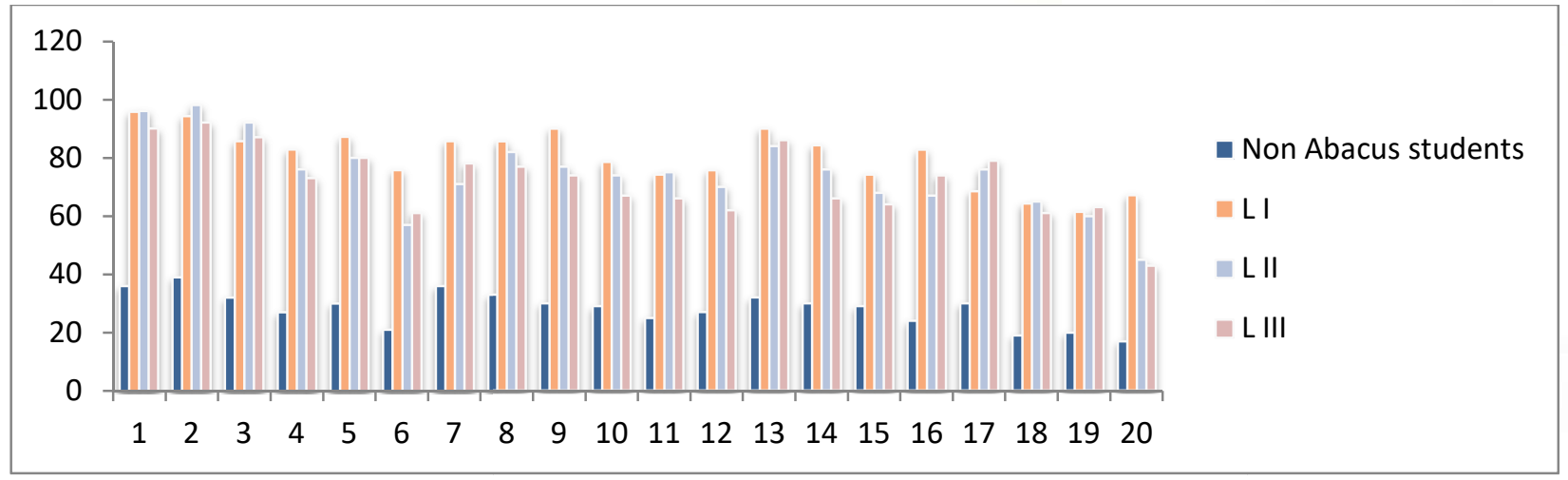

Fig 5. Comparative Individual Performance chart of abacus learners in each level 
On analyzing the results in table 1 shows statistical data collected before staring abacus programme and after each level up to level III. In Level I analysis is based on abacus sums and dictation sums, whereas level II is continued with visualization sums (without abacus) and in level III along with sums of addition, subtraction, multiplication is carried on abacus along with dictation on the same, not only this visualization (without abacus) sums of addition, subtraction, multiplication are also taken along with dictation. In level III students concentrate on the verbal communication sums and perform on it without abacus simply visualizing it. It clearly predicts that abacus learners are more superior to non abacus learners. At the starting the learners showed the mathematical solving capacity was increased in each level along with the development of different skills. Table1 measures the gradual max. Increase from 39 to 96 in L-I, from 39 to 98 in L-II and from 39 to 92 in L-III. The lower range (min.) has also increased from 17 to 61,17 to 45 and 17 to 43 in L-I, L-II and L-III respectively. Increase in lower range makes a major output predicted as increase in the different skills.

In fig 1 shows the increase in performance when compared from starting (before start of abacus programme). The gradual increase is seen in fig 2, 3 after level II and level III respectively. As the performance of abacus increases there is an increase in different skills such mathematical skills are developed, motivational, concentration, memory retention and recall, visualization skills are developed $[9,10]$. In fig 4 shows the individual development of abacus learners. In all the abacus learners there is growth seen. All the skills are development nearly thrice at the end of level III, indicated by three different colours each representing the levels. In fig 5 shows the comparative development taking place simultaneously.

\section{Conclusion:-}

On the basis of above discussion we concluded that there is enhancement in skill development of abacus learners when compared with non abacus learners. The skill development not only develops the personality of young generations and clears the fear of mathematics but also helps to create a strong generations in the environment.

\section{REFERENCES :-}

[1] Craiks FIM. (1964). Human memory. Annual Review of Psychology; v30: pp 63-102.

[2] Hatano, G.; Miyake, Y.\& Binks, M.G.(1977). Performance of expert abacus operators. Cognition, v5, pp 47-55.

[3] Hatta T, Ikeda K.(1988). Hemisphere specialization of abacus experts in mental calculation evidence from the results of time sharing tasks. Neuropsychologia ;v 26;pp 877-893.

[4] Hatta T.(1985). Hemi sphere functioning in Sorobon experts, shuzan-shunja v59: pp 2-26

[5] Hattano G, Osawa K.(1983). Digit memory of grand experts in abacus derived mental calculation, Cognition; v15, pp 95-110.

[6] Hope, J.A. \& Sherrill, J.M. (1987). Characteristics of unskilled and skilled mental calculators. Journal for Research in Mathematics Education, v18 (2), 98-111.

[7] Krampner, J. (1994). Ancient abacus: elegant, accurate, fun to operate. Dollar Sense, pp10-11. EBSCO host Full Display, Item No: 9403117506.

[8] Larry R, Squire, Jefrey G, Ojemann Francis M, Miezen.(1992). Neurobiology; Proc Nati Acad Science USA, v89, pp 1837-1841.

[9] Mythili B, Anu S, Sangeetha M,Vasanthi R.(2006). Evaluation of memory in Abacus Learners. Indian J Physiol Pharmacol ; v50 ( 3) : pp 225-233.

[10] Stigler JW. (1980) "Mental Abacus" the effect of Abacus training on Chinese children. Mental Calculation Cognitive, Psychol; v16;pp145-176.

[11]Tiwari Yogesh and Tiwari M. (2016). Evaluation of VAK skills (Visual, Auditory \&Kinesthetic Skill) in abacus Learners: International Advance Research Journal in Science, Engineering \&technology, Vol3, Issue $8, \quad$ pp- 197-202. DOI 10.17148/IARJSET.2016.3836.

[11] The effects of abacus learning on solving arithmetic problems (1999); A comparative study of elementary junior high school students at upper level and in experienced students. Journal of the Faculty of Education, Shinshu University, v 96, pp145-156.

[12] Effects of abacus learning on 3rd-graders performance in paper - and-pencil tests of calculation. (1989) Japanese Psychological Research; Vol. 31, No. 4, 161-168. (Joint work). 